\title{
The Trolley Problem and Intuitional Evidence
}

\author{
Sebastian J. Conte ${ }^{1}$ (D)
}

Accepted: 26 November 2021

(c) The Author(s) 2022

\section{Introduction}

It is a common assertion that the practice of treating intuitions as evidence figures centrally in philosophy. Following Herman Cappelen, ${ }^{1}$ we may refer to this assertion as Centrality. Recently, however, Centrality has been challenged. Most notably, Cappelen $^{2}$ and Max Deutsch ${ }^{3}$ have each written a book arguing that Centrality is false. They investigate Centrality by carefully analyzing philosophical articles and the use of cases in defending and challenging theories. Roughly, they find that philosophers argue for claims about cases, which they take to suggest that Centrality is false. The idea is that since claims about cases are supported by arguments, it is not clear that the intuitiveness of the claim is doing any work. Unless friends of Centrality can demonstrate that the intuitiveness of the claims is (also) doing some epistemic work, we should assume that the claims are supported by arguments (full stop). Thus, the onus is on friends of Centrality to show that intuitions actually do epistemic work.

In this paper, I take on this challenge by combining three strategies for examining Centrality. I apply these strategies to Judith J. Thomson's ${ }^{4}$ article on the trolley problem, which is an article also examined by Cappelen. The first strategy is to examine how philosophers argue. According to the framework I apply, ${ }^{5}$ if we want to know whether a certain claim is treated as evidence because of its intuitiveness, we should first consider whether it is treated as a starting point for an abductive argument. Second, if it is so treated, we should move on to consider whether intuition-terminology is used to refer to the claim. If that is the case, we have reason to believe that the claim is treated as evidence because of its intuitiveness. The second strategy is to

\footnotetext{
1 Herman Cappelen, Philosophy without Intuitions (Oxford: Oxford University Press, 2012), 3.

2 Cappelen, Philosophy without Intuitions, op. cit.

3 Max Deutsch, The Myth of the Intuitive. Experimental Philosophy and Philosophical Method (Cambridge, Massachusetts: MIT Press, 2015).

4 Judith J. Thomson, “The Trolley Problem," Yale Law Journal 9 (1985): 1395-1415.

5 Conte, Sebastian J. Are Intuitions Treated as Evidence? Cases from Political Philosophy. Manuscript.
}

Sebastian J. Conte

s.j.conte@stv.uio.no

1 Department of Political Science, University of Oslo, Oslo, Norway 
look at what an author states to be her evidence for a particular theoretical account. The third strategy is to look at what the philosophers write about their methodology.

Based on the findings of the analysis, I argue that, contrary to what Cappelen believes, Thomson treats intuitions about cases as evidence. Moreover, I argue that the analysis reveals that previous attempts at analyzing how philosophers argue (such as Cappelen's analysis) have considerable shortcomings. When applying the strategies of those previous studies, one runs the risk of not capturing the central features of intuitionistic methods-or even mistakenly interpreting these features as suggesting that Centrality is false.

I proceed as follows: First, I outline Cappelen's general project. Second, I present Cappelen's analysis of Thomson's article and some objections to his analysis. Third, I outline how Thomson describes her method. The section on Thomson's method serves various purposes. It brings to the fore the striking contrasts between how Thomson describes her method and what Cappelen argues is her method and thus motivates a reanalysis of it. Moreover, Thomson's description of her method provides the basis of the third strategy I apply in my analysis of her argumentation in her article on the trolley problem. Fourth, I analyze Thomson's article, applying the three strategies described above. Fifth, I argue that my analysis reveals some shortcomings of Cappelen's analysis of Thomson's article. Finally, I discuss some objections to my analysis and conclude.

\section{Backdrop}

Cappelen's analysis of Thomson's article is part of a bigger metaphilosophical project. Cappelen's ${ }^{6}$ aim is to correct an assertion-i.e., Centrality-that "is almost universally accepted in current metaphilosophical debates and figures prominently in our self-conception as analytic philosophers." Centrality has made philosophers engaged in first-order philosophy concerned about their disciplines as "they are unsure what intuitions are and whether they can carry the evidential weight we allegedly assign to them."7 Cappelen argues that Centrality is false and hence, that this concern is unwarranted.

Cappelen's project is wide-ranging, and his goal is to show that Centrality is false for analytic philosophy in general. He examines cases from a variety of philosophical disciplines, such as philosophy of mind and language, epistemology, and moral philosophy. The cases from Thomson's article on the trolley problem are among those from moral philosophy ${ }^{8}$ and are, according to Cappelen, ${ }^{9}$ the best illustration of how Centrality fundamentally misrepresents the philosophical practice. The aim of Thomson's article is to provide a solution to what she calls the trolley problem:

\footnotetext{
${ }^{6}$ Cappelen, Philosophy without Intuitions, op. cit., 1.

7 Ibid.

8 He also examines Thomson's ("A Defense of Abortion," Philosophy and Public Affairs 1, no. 1 (1971):

47-66) violinist case. However, I do not have space to examine that case in this paper.

${ }^{9}$ Cappelen, Philosophy without Intuitions, op. cit., 160.
} 
why may a bystander divert a trolley onto a track where it will kill one person to save five, while a surgeon may not take the organs from a young man, and thereby killing him, to save five people?

\section{Cappelen and the Trolley Problem}

Cappelen starts his discussion of Thomson's article by presenting two of the cases she considers: Trolley driver and Transplant. In Trolley driver, the only way for a trolley driver to avoid running over five people, and thereby killing them, is to divert the trolley onto another track where he will run over and kill one person. In Transplant, the only way for a surgeon to save five patients in need of new organs is to take the organs from a sixth patient and thereby kill him. These cases were first presented in Foot's article "The Problem of Abortion and the Doctrine of Double Effect." 10 Cappelen then notes how Thomson responds to these cases. She claims that everyone to whom she has presented the cases has responded that it is permissible for the driver to divert the trolley, but impermissible for the surgeon to operate. Cappelen then goes on to claim that Thomson, after having presented the cases, "immediately goes on to question these answers. She asks for reasons (i.e. arguments) for why these should be the correct answers." 11 To support this claim, he provides the following quote: ${ }^{12}$

Here then is Mrs. Foot's problem: "Why is it that the trolley driver may turn his trolley, though the surgeon may not remove the young man's lungs, kidneys, and heart?" In both cases, one will die if the agent acts, but five will live who would otherwise die-a net saving of four lives. What difference in the other facts of these cases explains the moral difference between them? ${ }^{13}$

Thus, according to Cappelen: ${ }^{14}$

A central goal of Thomson's paper is to question the answers given to questions asked about the cases. There is a tension between the two answers and that tension shows further reflection and investigation is needed. Thomson and Foot articulate the reasons that can be given for the initial answer.

He then presents what he understands to be Thomson's first take at how the claims about the cases can be justified by quoting a selection of passages from the article:

Killing one is worse than letting five die.

So the surgeon must refrain from operating.

\footnotetext{
${ }^{10}$ Philippa Foot, "The Problem of Abortion and the Doctrine of Double Effect," Oxford Review 5 (1976): 5-15.

${ }^{11}$ Cappelen, Philosophy without Intuitions, op. cit., 159-160, italics in original.

12 Ibid., 160.

13 Thomson, "The Trolley Problem," op. cit., 1396.

${ }^{14}$ Cappelen, Philosophy without Intuitions, op. cit. 160, italics in original.
} 
By contrast, the trolley driver's choice is between turning the trolley, in which case he kills one, and not turning the trolley, in which case he does not let five die, he positively kills them.

Now surely we can say

Killing five is worse than killing one.

But then that is why the trolley driver may turn his trolley: He would be doing what is worse if he fails to turn it, since if he fails to turn it he kills five. ${ }^{15}$

The latter quote is what Cappelen takes to be Thomson's arguments supporting the claims about Trolley driver and Transplant.

Cappelen then goes on to apply his analytical framework. He uses three diagnostics for identifying reliance on intuition as evidence. First, intuitive judgments have a special phenomenology; they seem true (F1). Second, intuitive judgments have a special epistemic status- "Rock," as Cappelen calls it (F2). This means that intuitive judgments have non-inferential justification and that they are evidence recalcitrant. Third, intuitive judgments are based solely on conceptual competence (F3). The absence of all three features in an argument, Cappelen thinks, "is very strong evidence that there is no reliance on the intuitive in [an] argument." 16

Cappelen thinks that the presence of F1 and F3 are indicated by an author explicitly stating that a claim has the relevant feature-that is, it either has a special phenomenology or is delivered by conceptual competence. When it comes to F2, however, he looks for evidence that is more implicit. Roughly, he thinks that a philosopher arguing for a claim gives us reason to believe the claim lacks the "Rock" status.

Cappelen's analysis of F1 and F3 is relatively brief. He more or less just remarks that Thomson makes no statements suggesting that the features are present. His discussion of F2, on the other hand, is lengthier. In short, he maintains that Thomson argues for the claim about the cases (see the quoted passage above). I will, following Jennifer Nado, ${ }^{17}$ refer to the view that Thomson argues for the claims about the cases and that this suggests that intuitions about the cases are not treated as evidence as the "argument from argumentation."

The argument from argumentation has been challenged by friends of Centrality. It has been objected that the presence of arguments need not be Centrality unfriendly. For example, arguments may be used as further support, ${ }^{18}$ or they may be abductive. ${ }^{19}$ If the arguments are abductive, the aim is to explain the intuition, and insofar

\footnotetext{
15 Ibid. The passages are collected from Thomson, “The Trolley Problem,” op. cit., 1396-1397.

16 Ibid., 114.

17 Jennifer Nado, “The intuition deniers," Philosophical Studies 173 (2016): 781-800.

18 John Bengson, "How philosophers use intuition and 'intuition'," Philosophical Studies 171 (2014): 555-576; Davis J. Chalmers, "Intuitions in philosophy: a minimal defense," Philosophical Studies 171 (2014): 535-544; Nado, "The intuition deniers," op. cit., 795; Jonathan Weinberg, "Cappelen between rock and a hard place," Philosophical Studies 171 (2014): 545-553.

19 Nado, "The intuition deniers," op. cit., 795, "Demythologizing intuition," Inquiry 60, no. 4 (2017): 386-402, 395-396; David Colaço and Edouard Machery, "The intuitive is a red herring," Inquiry 60, no. 4 (2017): 403-419, 413-415; Edouard Machery, Philosophy within its proper bounds (Oxford: Oxford University Press, 2017), 179-180.
} 
as a theoretical account can explain the intuition, the theoretical account is considered plausible. Thus, the direction of support is the opposite of what Cappelen suggests; it goes from the claim about the case to a theoretical account.

Cappele ${ }^{20}$ has, in response to these objections, claimed that it is not enough to argue that the presence of arguments need not be Centrality unfriendly. To push the debate forward, friends of Centrality need to come up with a method capable of providing positive evidence for Centrality-i.e., they have to show that the intuitiveness of a claim is actually doing epistemic work.

Moreover, there is a further complication that friends of Centrality have to deal with. According to Cappelen, finding claims that are not argued for is not positive evidence for Centrality. In fact, Cappelen finds some claims that Thomson does not argue for. He asserts that these claims are common ground and that there is therefore no need to appeal to their intuitiveness. ${ }^{21}$ Furthermore, he argues that we should resist the idea that the claim happens to be in the common ground because of its intuitiveness: notions such as "Rock" are elusive and controversial categories, whereas "common ground" is not. ${ }^{22}$

I think it is debatable whether Cappelen succeeds in establishing that the burden of evidence is on friends of Centrality. ${ }^{23}$ Nevertheless, Cappelen's challenges suggest some issues that warrant consideration. This paper offers some responses to these challenges.

\section{Thomson on her Method}

In her writings, Thomson is quite explicit about her reliance on an intuition-based method. ${ }^{24}$ She writes, for example, that a moral theory "is at the mercy" of moral intuitions about particular examples. ${ }^{25}$ Elsewhere, she writes that such judgments "serve as data for" moral theories. ${ }^{26}$ In yet another piece, she writes that

[...] the moral theorist must attend to his or her own moral beliefs about examples, stories, and cases, actual or invented, looking to see how those beliefs do (or do not) change as the details of the stories are altered. For it is precisely those beliefs which supply the data for moral theorizing, and which go a long way-if not all the way_-to setting the constraints on what constitutes an

\footnotetext{
${ }^{20}$ Cappelen, "Replies to Weatherson, Chalmers, Weinberg, and Bengson," Philosophical Studies 171 (2014): 577-600, 599-600.

21 Cappelen, Philosophy without Intuitions, op. cit., 153, 161.

22 Ibid., 154-155.

23 See e.g. Nado, "The intuition deniers," op. cit.

24 Thomson uses "belief," "judgment," and "intuition" interchangeably when referring to claims about cases.

25 Thomson, "Reply to Commentators," in Goodness and Advice, ed. Amy Gutman (Princeton: Princeton University Press, 2001): 147-179, 175.

26 Thomson, The Realm of Rights (Cambridge, Massachusetts: Harvard University Press, 1990), 4, italics in original. See also ibid., 33, "Précis of The Realm of Rights," Philosophy and Phenomenological Research 53, no. 1 (1993): 159-162, 159.
} 
acceptable moral principle, and thus on what constitutes an acceptable way of understanding what we ourselves take morality to require of us. ${ }^{27}$

From these quotes, I think it is quite clear that Thomson claims to be treating intuitions as evidence. She explicitly refers to them as "data." She claims that moral theories are at the mercy of intuitions and that intuitions set the constraints on what constitutes an acceptable theoretical account. Thus, theoretical accounts, in Thomson's view, should conform to our moral intuitions.

Moreover, she claims that the method she applies

[...] is like the process Rawls describes as the effort to reach 'reflective equilibrium', with this proviso: on Rawls' account of the matter, everything is provisional, everything is open to revision, whereas I am suggesting that some moral judgments are plausibly viewed as necessary truths and hence not open to revision. ${ }^{28}$

In this passage, she not only claims that intuitions are evidence but that they are very strong evidence. Some intuitions even are not open to revision.

To sum up, Thomson explicitly states that she treats intuitions about cases as "data." Moreover, some intuitions are treated as very strong evidence, as they are not open to revision. Interestingly, Thomson's description of her method starkly contrasts Cappelen's findings. Thus, it is worth taking a new look at Thomson's article.

\section{A Reanalysis of Thomson's Article}

In this section, I do a reanalysis of Thomson's article and apply several strategies to this endeavor. First, I apply an analytical framework developed in Anonymous. ${ }^{29}$ Second, I look at what Thomson states is her evidence for or against the theoretical accounts she discusses in her article. Third, I consider what Thomson writes about the method she claims to apply. ${ }^{30}$

\footnotetext{
27 Thomson, "Afterword," in Rights, Restitution, and Risk. Essays in Moral Theory, ed. William Parent (Cambridge, Massachusetts: Harvard University Press, 1986): 251-260, 260.

28 Thomson, The Realm of Rights, op. cit. (1990), 32 n. 20.

29 Conte, op. cit.

30 Other counter-readings of Cappelen's cases have been offered. Chalmers, for example, provides a counter-reading of his own "zombie argument." Chalmers, op. cit. Chalmers claims that the observations that Cappelen takes to undercut the support for Centrality are in fact consistent with Centrality. Ibid., 540-541. While Chalmers mentions some possible sources of positive evidence for Centrality, Cappelen argues that Chalmers falls short of providing any positive evidence for Centrality. Cappelen, Philosophy without Intuitions, op. cit., 584-587. For example, Chalmers mentions that there is extensive intuitiontalk in philosophical texts and that many philosophers claim that they rely on intuitions as evidence. However, he does not engage with Cappelen's objections to the strategy of treating intuition-talk as evidence for Centrality. Nor does he engage with Cappelen's claim that philosophers have false secondorder beliefs. Thus, while Chalmers argues that Cappelen's observations are consistent with Centrality, my strategy is to go beyond Cappelen's observations and investigate if further observations about what Thomson is doing allow us to discriminate between Cappelen's (Centrality unfriendly) reading of the text and a Centrality supporting reading of the text. Moreover, I engage with Cappelen's arguments concerning intuition-talk and second-order beliefs. Thanks to a reviewer for the journal for encouraging me to
} 


\subsection{Arguments}

The analytical framework ${ }^{31}$ consists of two steps. The first step is to find out whether claims about cases are treated as starting points for abductive arguments. This step is in line with some of the responses to Cappelen, suggesting that many philosophical arguments are in fact abductive, which means that the direction of support goes from claims about cases to theoretical accounts. However, the framework expands on this strategy by offering a set of diagnostics that help determine whether the direction of support goes from the claims to the theoretical accounts or the other way. The diagnostics, which I will refer to as the "abduction features," are as follows:

When a claim about a case, $c$, is treated as a starting point for an abductive argument:

(i) Not-c is typically not a salient option.

(ii) Several theoretical accounts are under consideration.

(iii) A theoretical account is considered more/less plausible if it can/cannot explain $\mathrm{c}$, all else being equal. ${ }^{32}$

(i) indicates that the point of the inquiry is not to find out how to judge the case and that $\mathrm{c}$ is taken for granted. If, on the contrary, not-c is a salient option, this could suggest that the aim of the discussion of the case is to make (and justify) a judgment about the case. This provides us with reason to believe that the argument in question is not an abductive one. ${ }^{33}$ Moreover, if only one theoretical account is under consideration, this provides us with further reason to believe that the aim of the discussion is to judge the case, as the theoretical account seems to be taken for granted. Thus, this suggests that the theoretical account is used to eliminate or support the case verdict. This is not to say that the purpose of philosophical debates is to provide answers to questions about specific cases. Rather, the cases are used to raise interesting questions, ${ }^{34}$ the answers to which inform the more general philosophical question under debate. The presence of (ii), however, indicates that one is trying to decide which theoretical account is more plausible. To be more specific, the idea is that when there are several theoretical accounts that apply to the case, it gives us

\footnotetext{
Footnote 30 (continued)

distinguish my strategy from Chalmers'.

In addition, it is worth mentioning that Kevin Tobia offers a counter-reading of Thomson's article. Tobia, "Philosophical Method and Intuitions as Assumption," Metaphilosophy 46, nos. 4-5 (2015): 575594. However, Tobia's analysis of Thomson's argument is rather short, and he does not explicitly engage with the challenges noted in Section 3 of this paper. That said, Tobia's reading is similar to the one I offer.

31 Conte, op. cit.

32 The original framework also includes a fourth feature (roughly, that claims about new cases are introduced as arbiters when several competing theoretical accounts can explain c), but I have not included it here since it is not necessary to show that Thomson treats case verdicts as starting points for abductive arguments. It suffices to show that (i), (ii), and (iii) are present.

33 Cappelen, Philosophy without Intuitions, op. cit., 122-123.

34 Ibid., 188.
} 
reason to believe that the theoretical accounts are under consideration and are not provided as support for $\mathrm{c}^{35}$

However, the presence of (i) and (ii) need not suggest that c provides the theoretical account with any (theory) independent credibility; for example, the support could go in both directions. ${ }^{36}$ However, the presence of (iii) indicates that $\mathrm{c}$ has some credibility independent of the theoretical account in virtue of which it confers credibility onto the theoretical account. The presence of (i), (ii), and (iii), then, suggests that the claim is used as a starting point for an abductive argument and thus is treated as evidence.

However, cf. Cappelen, it is possible that some claims are so treated because they are common ground for some extra-intuitive reason. Thus, we need a strategy for finding out whether the claim is used as a starting point because of its intuitiveness. This brings us to the second step of the method: If intuition-terminology is used to describe the claim, then we have reason to believe that the claim is used as a starting point because of its intuitiveness. ${ }^{37}$ Here are some examples of such intuition-terminology:

$$
\begin{aligned}
& \text { "Intuition," "intuitive(ly)," "seem," "look," "see," "what we would say," "feel," } \\
& \text { "clear(ly)," and "obvious(ly)." } 38
\end{aligned}
$$

To sum up, the method can be portrayed as a decision tree (see Fig. 1). First, we ask whether the abduction features are present. If "no," then the claim is not a starting point of an abductive argument. If "yes," we go on to consider whether intuitionterminology is used when making the claim or when referring to it. If we do not find such terminology, this could suggest that the claim is common ground for some extra-intuitive reason (or that the source of the claim is not mentioned). If we find such terminology, we have reason to believe that the claim is treated as evidence because of its intuitiveness. ${ }^{39}$

\footnotetext{
35 Thanks to a reviewer of the journal for pressing me to clarify these points.

${ }^{36}$ Cappelen, Philosophy without Intuitions, op. cit., 123; Max Deutsch, "Replies to commentators," Inquiry 60, no. 4 (2017): 420-442, 425.

${ }^{37}$ Since the framework does not treat the presence of intuition-terminology by itself as a sufficient condition for believing that intuitions are treated as evidence, the framework avoids the objections against relying on the use of intuition-terminology. See e.g. Cappelen, Philosophy without Intuitions, op. cit., Part 1. For a more complete discussion of that issue, see Conte, op. cit. See also the discussion in Section 7.2.

${ }^{38}$ Bengson, op. cit., 561.

39 This approach may seem to be similar to that of James Andow. James Andow, "Abduction by Philosophers: Reorienting Philosophical Methodology," 47, no. 3 (2016): 353-370. However, Andow does not focus on abductive arguments as such. Ibid., 362. He suggests that Cappelen only denies "that philosophers rely on intuitions as construed in certain very particular ways as evidence in a distinctive way." Ibid., 357, italics in original; but see Cappelen, Philosophy without Intuitions, op. cit., 3, 18. I focus specifically on the question of whether intuitions are treated as starting points for abductive inferences and argue that Cappelen's interpretation of Thomson's arguments is wrong. Thus, my disagreement with Cappelen cannot be reduced to a disagreement about how to understand Centrality.
} 


\subsubsection{The Abduction Features}

Not-c is typically not a salient option: When Thomson presents cases describing actions, it is almost always the case that the actions "seem," "feel," "obviously are," or "clearly are" either permissible or impermissible (c). The opposite claim (not-c) is not considered an option. For example, the possibility that it is permissible for a surgeon to take the organs from a healthy patient to save five others is never under consideration.

Some of the theoretical accounts that Thomson considers have not-c as an implication. Nevertheless, this does not make Thomson consider not-c a salient option. If a theoretical account has implications that conflict with a claim about a case, her reaction is to revise the theoretical account. Thus, if a theoretical account has not-c as an implication, this is considered as something that counts against the theoretical account and may call for revision or even rejection of it, but not as a reason to consider not-c.

Here is an example: Thomson presents the following theoretical account from Foot: "(II) Killing five is worse than killing one." 40 To assess this theoretical account, she considers alternate versions of the Transplant. In these versions, the surgeon is responsible for the five persons needing new organs to survive, either due to carelessness or because he wanted to kill them (but later repents). To the question of whether the surgeon may cut open the one and distribute his organs to the five, Thomson responds, "I should think plainly not." ${ }^{41}$ She then goes on to consider how that claim reflects on (II):

There are two ways in which we can go here. First, we can say: (II) does tell us that the surgeon ought to operate, and that shows it is false. Second, we can say: (II) does not tell us that the surgeon ought to operate, and it is true. ${ }^{42}$

What she is claiming, then, is that the truth of (II) is contingent on whether it is consistent with the claim (c) about the alternate version of the Transplant. If the implication of (II) is not-c, then it is "false." If the implication of (II) is c, then it is "true."

Several theoretical accounts are under consideration: Thomson considers several theoretical accounts. For example, in addition to (I) and (II), she considers a revised version of (II):

(ii') If a person is faced with a choice between doing something here and now to five, by the doing of which he will kill them, and doing something else here and now to one, by the doing of which he will kill only the one, then (other things being equal) he ought to choose the second alternative rather than the first. ${ }^{43}$

\footnotetext{
40 Thomson, "The Trolley Problem," op. cit., 1397.

41 Ibid., 1399.

42 Ibid., 1400.

43 Ibid., italics in original.
} 
Are the abduction features present?

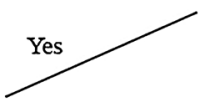

Are the claims referred to using intuition-terminology?

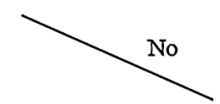

The claims are not starting points for abductive arguments

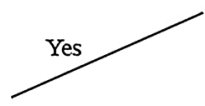

The claims are treated as evidence because of their intuitiveness

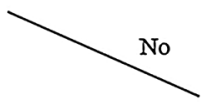

The claims may be treated as evidence for some extraintuitive reason

Fig. 1 The analytical framework (Figure from Conte, op. cit.)

Moreover, she considers the Kantian idea that you should always treat persons as an end and never as a means ${ }^{44}$ and the idea that "it is not morally required of us that we let a burden descend out of the blue onto five when we can make it instead descend onto one if we can make it descend onto the one by means which do not themselves constitute infringements of rights of the one." 45

A theoretical account is considered more/less plausible if it can/cannot explain $c$ : A clear example of a theoretical account being considered plausible if it can explain claims about cases, and implausible if it cannot, is the example mentioned above when discussing feature (i). (II) is true if it can explain c, but false if it cannot.

Another example is Thomson's discussion of the first part of Foot's principle"(I) Killing one is worse than letting five die." 46 In that discussion, she introduces the bystander case (henceforth, Bystander): a bystander may throw a switch, and thereby turn a trolley that otherwise would have killed five persons onto a track where it will only kill one. Thomson's "feeling" is that the bystander may throw the switch. ${ }^{47}$ She continues by saying that "If [the bystander] may [throw the switch], there is serious trouble for Mrs. Foot's thesis (I)" and that "If thesis (I) were true, it would follow that the bystander may not throw the switch, and that I am taking to be false." ${ }^{, 48}$ Hence, since (I) is in conflict with the feeling about the switch case, which she takes to be true, (I) is considered to be less plausible than it otherwise would have been. Consequently, Thomson goes on to search for other theoretical accounts that are consistent with the claims about Bystander and the other cases.

To sum up, Thomson's approach is the following: She starts with a set of cases and a theoretical account that is supposed to account for these cases and that she wants to investigate. To investigate the accounts, she constructs new cases. In these cases, there is only one salient option (i). If the account is inconsistent with a claim

\footnotetext{
44 Ibid., 1401.

45 Ibid., 1409, italics in original.

46 Ibid., 1396.

47 Ibid., 1397, 1398.

48 Ibid., 1398-1399.
} 
about a case, she revises the theoretical account and further investigates it by constructing new cases ([ii] and [iii]). She does this until she comes up with an account she deems satisfactory. The presence of features (i), (ii), and (iii), then, suggests that Thomson is treating claims about cases as starting points for abductive arguments.

\subsubsection{Intuition-Terminology}

Thomson consistently refers to claims about cases using intuition-terminology. Sometimes she refers to how she or people in general "feel" about a case ${ }^{49}$ and how things "seem." "obvious" and "clear." 52 Moreover, when discussing what she calls the "distributive exemption," she explicitly refers to such claims as intuitions:

I do not find it clear why there should be an exemption for, and only for, making a burden which is descending onto five descend, instead, onto one. That there is seems to me very plausible, however. On the one hand, the agent who acts under this exemption makes be a threat to one something that is already a threat to more, and thus something that will do harm whatever he does; on the other hand, the exemption seems to allow those acts which intuition tells us are clearly permissible, and to rule out those acts which intuition tells us are clearly impermissible. ${ }^{53}$

What Thomson is saying is that the fact that the exemption is consistent with our intuitions about acts counts in favor of the exemption's plausibility. Note that the acts which "intuition" tells us are permissible or impermissible are the acts depicted in the cases Thomson discusses-e.g. Transplant, Trolley driver, and Bystander. ${ }^{54}$

In sum, that Thomson treats claims about cases as starting points for abductive arguments and refers to them using intuition-terminology suggests that she treats the claims as evidence because of their intuitiveness.

\footnotetext{
49 Ibid., 1397, 1398, 1403, 1412.

50 Ibid., 1398, 1403, 1408.

51 Ibid., 1399, 1407.

52 Ibid., 1411.

53 Ibid., 1408, Thomson's italics omitted, mine added.

54 A critic might want to point out that when Thomson is commenting on the Transplant and Trolley she writes that "[e]verybody to whom I have put this [...] case says" Yes/No. Ibid., 1395-1396. These statements could suggest that Thomson has a fairly good idea about what her peers think about the cases and is possibly appealing to these claims because they are in the common ground (and that they are in the common ground for all kinds of different reasons, but not because they are intuitive). First, formulations such as "what people would say" about a case can be used to indicate what intuitions people have about a case. Second, I do find it hard to interpret the passage cited in this section in a way that supports this reading of Thomson, in particular when taking into account the second and third strategies of my analysis.
} 


\subsection{Explicit Statements}

A second strategy is to look at what an author states is her evidence for or against the theoretical accounts she discusses in her article. For example, we might look for whether an author claims she is engaging in abductive reasoning and at what she claims is the starting point of such reasoning. Cappelen ${ }^{55}$ thinks that looking for such statements is an "obvious" way of approaching the question of whether an author engages in abductive reasoning. Interestingly, Cappelen ${ }^{56}$ claims that "in none of the cases [he investigates] is there any explicit statement like that." In this section, I examine several passages from Thomson in which I argue there are, contrary to what Cappelen claims, such statements. Moreover, I also look for explicit statements of intuitions (about cases) being treated as evidence for, or reasons for accepting, a theoretical account.

\subsubsection{Abductive Arguments}

Let us start with considering whether Thomson is explicitly stating that she engages in abductive reasoning. When arguing abductively, one treats some claims as datum and infers that the hypothesis (derived from, for example, a theoretical account) that best explains the datum is true. ${ }^{57}$

Thomson explicitly calls for theoretical accounts that can explain the claims about the cases under consideration. ${ }^{58}$ Here are a couple of examples:

1. ... I propose we grant that both the bystander and the surgeon would infringe a right of their ones, a right in the cluster of rights that the ones' have in having a right to life, and that we look for some other difference between the cases which could be appealed to to explain the moral difference between them. ${ }^{59}$

2. As I shall put it, shoving a person, toppling a person off a footbridge [i.e., what the person in the footbridge case must do to save the five], are themselves infringements of rights of his. A theory of rights ought to give an account of what makes it be the case that doing either of these things is itself an infringement of a right of his. But I think we may take it to be a datum that it is, the job which confronts the theorist of rights being, not to establish that it is, but rather to explain why it is. $^{60}$

The first quote is preceded by a discussion of whether the morally relevant difference between Bystander and Transplant is that the bystander would not infringe

\footnotetext{
55 Cappelen, Philosophy without Intuitions, op. cit., 122.

56 Ibid.

57 John R. Josephson and Micheal C. Tanner, "Conceptual analysis of abduction," in Abductive Inference. Computation, Philosophy, Technology, ed. John R. Josephson and Susan G. Josephson,. (Cambridge: Cambridge University Press, 1996): 5-30, 5.

58 See e.g. Thomson, “The Trolley Problem,” op. cit., 1396, 1400, 1401, 1404, 1405, 1409, 1410.

59 Ibid., 1406, italics in original.

60 Ibid., 1409, Thomson's italics omitted, mine added
} 
a right of the one on the other track by diverting the trolley, whereas the surgeon would infringe a right of the sixth patient by operating. However, she argues that both the bystander and the surgeon infringe a right of the persons in question by proceeding, and thus that this difference cannot explain the claims about the casesi.e., that the bystander may proceed, whereas the surgeon may not. I think, therefore, that by using "explain" in the first quote, Thomson is signaling that she is engaging in abductive reasoning and treating the claims about the cases as datum.

In the second quote, Thomson explicitly states that she treats the claim that "shoving a person, toppling a person off a footbridge are themselves infringements of a right of [the person]" as "datum." Moreover, she claims that the job that confronts us is not to establish such claims, but to provide a theoretical account that can explain them. The second quote, then, leaves little room for doubting that Thomson is stating that she is engaging in abductive reasoning. (Note that the point of explaining the datum is not to shore up the claim treated as datum. Thomson explicitly states that our job is not to establish this (or these) claim(s).)

\subsubsection{The Role of Intuitions}

When considering whether Thomson states that intuitions serve as evidence for or against a claim, the paragraph in which Thomson considers the distributive exemption is worth having a closer look at:

I do not find it clear why there should be an exemption for, and only for, making a burden which is descending onto five descend, instead, onto one. That there is seems to me very plausible, however. On the one hand, the agent who acts under this exemption makes be a threat to one something that is already a threat to more, and thus something that will do harm whatever he does; on the other hand, the exemption seems to allow those acts which intuition tells us are clearly permissible, and to rule out those acts which intuition tells us are clearly impermissible. ${ }^{61}$

In this paragraph, Thomson mentions two reasons that make it plausible that there is an exemption for making a burden that is descending onto five descend, instead, onto one. It is the second reason that is of particular interest. Thomson is claiming that the exemption allows those acts which intuition tells us are clearly permissible and rules out those acts which intuition tells us are clearly impermissible is a reason to think that the exemption is plausible. This, then, is an example of Thomson explicitly stating that she treats intuitions as evidence.

\subsection{Beliefs About Methodology}

A third strategy is to consider what an author has said or written about her methodology. According to this strategy, when we want to know what method an

61 Ibid., 1408, my italics. 
author applies in a particular text, we can consult other texts by the author to make inferences about the method in the text we are interested in. In Section 4, I outlined Thomson's methodological views, drawing on several sources. The outline in Section 4 revealed that Thomson believes that we should treat intuitions as evidence, and this therefore gives us reason to believe that she treats intuitions as evidence.

\section{Explaining Why Cappelen is Wrong}

Above, I pursued several strategies in trying to answer the question of whether Thomson treats intuitions as evidence. The strategies unanimously answer the question in the affirmative. Although I think my analysis provides a strong defense of Centrality on its own, it would further strengthen it if I were able to account for the findings of Cappelen's study and explain where his analysis goes wrong. That is what I attempt to do in this section.

First, Cappelen claims that Thomson "asks for reasons." In Section 5.2.1, I hinted at a response to this claim. It is worth noting that Thomson does not ask for reasons but rather explanations. Thomson's request, then, is by the very least, not something that counts against the assumption that Thomson engages in abductive reasoning. Thus, a shortcoming of Cappelen's study is that he fails to take seriously the possibility that what he assumes are reasons supporting claims are rather explanations of them.

Second, as I outlined in Section 3, Cappelen provides a suggestion for what we might think is an argument that Thomson provides for the claims about Transplant and Trolley driver. However, my analysis suggests that Thomson does not deduce the claims from the theoretical accounts, but rather treats the claims as starting points for abductive arguments in which the acceptance of the theoretical accounts figures as the conclusion. Nothing in the passage that Cappelen cites contradicts my interpretation of Thomson's arguments. However, some of the findings of my study contradict the view that Thomson is arguing for the claims. In particular, the presence of the abduction features strongly suggests that the theoretical accounts she is discussing are not used to support the claims about the cases. Rather, the direction of support is the opposite. For example, the first premise in what Cappelen takes to be Thomson's argument, as argued in Section 5.1.2, is a theoretical account that Thomson rejects because it cannot explain the claim about Bystander. Moreover, although what apparently supports the claim about Transplant is rejected, Thomson does not weaken her commitment to the claim. Thus, a shortcoming of Cappelen's study is that his analysis is too narrow in the sense that he considers too few cases and theoretical accounts to get a proper grasp of the dialectic of Thomson's article. 


\section{Objections and Replies}

In this section, I consider some objections to my analysis. First, I consider objections to the second and third strategy. Then, I consider objections to the first strategy.

\subsection{Philosophers Have False Second-Order Beliefs}

Several intuition-deniers have claimed that we should not put too much emphasis on philosophers' self-analyses. ${ }^{62}$ If they are right, that might seem to pose a problem for the current analysis. Both the second and third strategy heavily rely on philosophers' self-analyses. Let us, therefore, consider the arguments used to support this claim in more detail.

Both Cappelen ${ }^{63}$ and Deutsch ${ }^{64}$ mainly support the claim that philosophers have false second-order beliefs about their methods by appealing to the findings of their case studies. However, Deutsch does not analyze Thomson's arguments, and I have argued that the findings of Cappelen's analysis are contestable.

Molyneux, on the other hand, offers some arguments that do not depend on the findings of such analyses. Molyneux ${ }^{65}$ claims that "individuals are often unaware of what is truly guiding their practice, and tend to manufacture post hoc rational motivations when challenged," and he cites a study by Richard E. Nisbett and Timothy DeCamp Wilson ${ }^{66}$ to support the claim. Moreover, he thinks that the fact that "epistemologists prior to Gettier (1963) mistakenly thought that they were disposed to apply the term 'knowledge' only to cases of justified true belief' illustrates that "philosophers should already be aware of the dangers of privileging their own selfanalyses." ${ }^{\prime \prime}$ Finally, he maintains that "[u]nless there is some good reason why we might misanalyze our own application of a central term yet not be prone to misanalyzing our own application of a central method, we must be cautious about placing too much weight on our own supposed self-knowledge." 68

It is not clear to me to what extent Molyneux's observation about epistemologists' application of the term "knowledge" compels us to doubt philosophers' selfanalyses. Linda Zagzebski ${ }^{69}$ claims that " $[\mathrm{t}]$ he moral drawn in the thirty years since Gettier published his famous paper is that either justified true belief (JTB) is not sufficient for knowledge, in which case knowledge must have an 'extra' component in addition to JTB, or else justification must be reconceived to make it sufficient for

\footnotetext{
62 Ibid., 164; Bernard Molyneux, "New Arguments That Philosophers Don't Treat Intuitions as Evidence," Metaphilosophy 45, no. 3 (2014): 441-461, 445; Deutsch, op. cit. (2015), 39.

63 Cappelen, Philosophy without Intuitions, op. cit., 163.

64 Deutsch, The Myth of the Intuitive, op. cit., 39.

65 Molyneux, op. cit., 163.

66 Richard E. Nisbett and Timothy De Camp Wilson, "Telling More Than We Can Know: Verbal Reports on Mental Processes," Psychological Review 84, no. 3 (1977): 231-259.

67 Molyneux, op. cit., 445

68 Ibid.

${ }^{69}$ Linda Zagzebski, 1994. "The Inescapability of Gettier Problems." The Philosophical Quarterly 44, no. 174 (1994): 65-73, 65, italics in original.
} 
knowledge." This does not entail that the epistemologists' self-analyses were completely off the mark.

Moreover, I doubt that Nisbett and Wilson's study provides us with a reason to believe that we should not trust philosophers' self-analyses of their methods. To explain why I do so, it would be helpful to consider some of the studies they conduct. Nisbett and Wilson ${ }^{70}$ conducted two studies in which participants were invited to evaluate an array of articles of clothing. Unbeknownst to the participants, the articles were identical. The authors found that the position of the object influenced the participants' evaluation of the articles of clothing. When asked which article of clothing was the best quality, the right-most object in the array was heavily overchosen. When asked about the reasons for their choices, however, none of the participants mentioned the position of the article in the array. Moreover, when explicitly asked about whether the position of the article may have influenced their choice, "virtually all subjects denied it..."71

When comparing epistemologists and the participants in Nisbett and Wilson's studies, there are some significant differences. While the participants are clueless with regard to what factors influence their reasoning, epistemologists seem to be able to identify (at least) some important characteristics of the cases to which they apply the term "knowledge." Second, while the participants in Nisbett and Wilson's studies doubted or denied that the stimuli they were subjected to influenced their judgments or behavior, the epistemologists did not deny the shortcomings of the JTB account of knowledge when confronted with the cases presented by Gettier. Moreover, even if epistemologists were — or are, for that matter-unaware of what makes them inclined to think that "knowledge" applies to a certain case, I do not see why it should follow that they are not able to describe the method they apply to find out when or why "knowledge" applies. ${ }^{72}$

\subsection{Objections Concerning the Analytical Framework}

Some critics may have doubts concerning the analytical framework I applied as a part of the first strategy for testing Centrality. For example, it has been argued that showing that claims about cases are treated as starting points for abductive arguments does nothing to refute the argument from argumentation. ${ }^{73}$ The idea seems

\footnotetext{
$\overline{70}$ Nisbett and Wilson, op. cit., 243-244.

71 Ibid., 244.

72 Perhaps an objector might try to challenge the reliability of philosophers' second-order beliefs by pointing out that Thomson claims, as quoted above, that "some moral judgments [... are] not open to revision," but in one of her recent articles, she revises the judgment about the switch case. Thomson, "Turning the Trolley," Philosophy \& Public Affairs 36, no. 4 (2008): 359-374. She no longer thinks that it is permissible to turn the trolley in that case. This is an interesting objection, but I do not have space to discuss it here as it raises bigger methodological questions, such as to what extent one should analyze articles in isolation or in relation to other articles by the same author, or as part of a greater debate. So, while such a question deserves thorough discussion, I can only offer some preliminary responses to the objection here. First, it is worth noting that Thomson uses the qualifier "some" in the quote. Moreover, it could plausibly be suggested that what Thomson is doing in that article is to introduce further intuitions and that she considers the intuitions about the switch case in light of (among other things) intuitions about other cases.

73 Cappelen, Philosophy without Intuitions, op. cit., 214-125; Deutsch, The Myth of the Intuitive, op. cit., 96, "Replies to commentators," op. cit., 425.
} 
to be that when such claims are treated as starting points for-or explanandum in-abductive arguments in which a theoretical account figures as the explanans, the direction of support is likely to go both ways. When that is the case, we lack a positive reason to assume that the claims about the cases are treated as having any independent credibility, and should therefore assume that they are not treated as evidence. Thus, according to this objection, the first step of the analytical framework fails to detect whether claims about cases are treated as evidence.

Moreover, some question that intuition-terminology indicates that an author finds the claim that is described using such terminology intuitive. ${ }^{74}$ Instead, such terminology could be used as hedge terms-i.e., to indicate that one is weakening one's commitment to the claim. Consequently, intuition-terminology need not indicate that claims are treated as evidence-or are in the common ground-because they are intuitive.

There are some things to be said in response to these objections. ${ }^{75}$ However, let us, for the sake of argument, grant the objections. Let us, moreover, again for the sake of argument, assume that philosophers' testimonies based on self-analyses (cf. strategies 2 and 3) do not provide us with a positive reason to believe that Centrality is true. Thus, the three strategies I apply demonstrate only that it is possible that Thomson treats intuitions as evidence, but does not provide positive evidence for believing so. Thus, none of the strategies succeeds in responding to Cappelen's challenge.

Is there anything more to be said by a friend of Centrality? I think there is. Although none of the strategies may be capable of providing positive reasons for believing that Centrality is true on their own, they might be when we combine them. If a philosopher claims that she applies a method according to which intuitions serve as evidence (cf. strategy 3 ), and the philosopher explicitly states that she treats a theoretical account as being able to account for our intuitions as a reason for thinking the account is plausible in her discussion of a particular first-order issue (cf. strategy 2), and if, when we examine the ways in which the philosopher actually argues, the ways she argues fit very well with what she claims (cf. strategy 1), then we should assume that she does what she says she is doing. Thus, we should assume that Thomson treats intuitions as evidence.

\section{Conclusion}

In this paper, I have explored three strategies for investigating Centrality. I have applied these strategies to Thomson's article about the trolley problem. Cappelen also examined this article, considering it a good example of how Centrality misrepresents the philosophical practice. The first strategy was to examine how philosophers argue, applying an analytical framework that helps us determine whether a claim is treated as a starting point for an abductive argument, and hence evidence,

\footnotetext{
${ }^{74}$ Cappelen, Philosophy without Intuitions, Part 1; Cian Dorr, "Review of Every Thing Must Go: Metaphysics Naturalized, by James Ladyman and Don Ross," Notre Dame Philosophical Reviews 6 (2010).

${ }^{75}$ Conte, op. cit.
} 
because of its intuitiveness. The second strategy was to look at what an author states is her evidence in a discussion of a particular issue. The third strategy was to look at what the philosopher writes about her methodology. All three strategies yield the same conclusion: Thomson treats intuitions as evidence.

The implications of my findings are, first, that Cappelen's approach has certain shortcomings. It does not capture the central features of intuition-based methods and even mistakenly interprets some of these features as suggesting that Centrality is false. This, I think, points to a more general critique of Cappelen's method and thus his project more generally. Second, since Thomson treats intuitions as evidence, it is, in particular, questionable whether Cappelen manages to show that Centrality is false with regard to moral philosophy.

Acknowledgements Earlier versions of this paper were presented at the Nordic Network of Political Theory's workshop (Oslo 2019) and a PhD workshop at the Department of political science, University of Oslo (Oslo 2019). The paper have benefitted from the discussions at these events and I am grateful to the participants at these events for their comments. The paper also benefitted from a stay at CAS as a GOODPOL-fellow. In particular, I would like to thank Robert Huseby, Jakob Elster, Cathrine Holst, Frej Klem Thomsen, Sigurd Lindstad, Hallvard Sandven, Sune Lægaard, Nina Maureen Cadorin, Even Hellan Larsen, Klemens Kappel, and an anonymous reviewer for the journal.

Funding Open access funding provided by University of Oslo (incl Oslo University Hospital).

Open Access This article is licensed under a Creative Commons Attribution 4.0 International License, which permits use, sharing, adaptation, distribution and reproduction in any medium or format, as long as you give appropriate credit to the original author(s) and the source, provide a link to the Creative Commons licence, and indicate if changes were made. The images or other third party material in this article are included in the article's Creative Commons licence, unless indicated otherwise in a credit line to the material. If material is not included in the article's Creative Commons licence and your intended use is not permitted by statutory regulation or exceeds the permitted use, you will need to obtain permission directly from the copyright holder. To view a copy of this licence, visit http://creativecommons.org/licen ses/by/4.0/.

Publisher's Note Springer Nature remains neutral with regard to jurisdictional claims in published maps and institutional affiliations. 